\title{
Mastering science in the South
}

\author{
To develop much-needed research capacity, developing countries cannot rely on theindustrialized world, \\ but haveto find their own specific solutions
}

Mauriziolaccarino

\begin{abstract}
"Creation, mastery and utilization of modern science is basically what distinguishes the South from the N orth." Abdus Salam, 1979 N obel Laureate for Physics (U NESCO, 1999a; Fig 1)
\end{abstract}

$\mathrm{E}$ ver since scientific research assumed central role in developed societies, science and technology have become fundamental prerequisites for the economic and social survival of advanced countries. Research itself has become a major industry in modern times, and is rewarded with large budgets and populated by many highly skilled professionals. Industrialized countries accordingly give high priority to research and development $(R \& D)$, as shown by the percentage of their gross domestic product that is devoted to $R \& D$. Western Europe and North America, which represent only $10 \%$ of the world's population, spend more than $60 \%$ of the world's gross expenditure on $R \& D$ (Table 1 ).

Developing countries, despite collectively representing the vast majority of the Earth's population, spend much less, both in absolute terms and as a percentage of their gross national product, with dire consequences for their economies and societies. And, as a result of economic and other problems, they are not in a position to increase their commitment to science and technology. Even if developing countries decided to increase their spending on $R \& D$, without adequate planning it would still be difficult for them to conduct and support research in an efficient way. Science is a complex activity that requires support from a sophisticated infrastructure, a good educational system and the social acceptance of budgetary choicesfactors that are not necessarily a given in most developing countries.

To address the wide discrepancy in $R \& D$ spending and activities between the developed and the developing world, as well as the ensuing economic, social and health problems, many politicians assume that fundamental research would be better carried out in the rich countries of the North while developing countries rely on existing technology. In fact, they believe that scientific research is not only expensive, but also requires an appropriate educational, social and cultural environment. In line with these ideas, the United Nations Conference on Science and Technology for Development, held in 1979 in Vienna, Austria, concluded that the industrialized world should assist the developing countries by transferring technology and products to them (UNCSTD, 1979). Although several such initiatives were started after the conference, they did not significantly contribute to development and often failed to achieve their goals: the improvement of social and economic conditions. A lack of adequately skilled professionals resulted in poor maintenance and the eventual breakdown

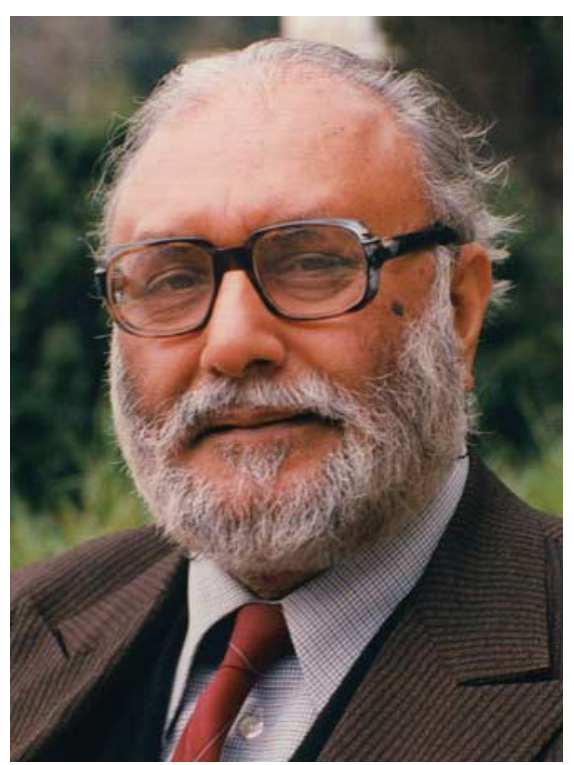

Fig1 | Abdus Salam, 1979 Nobel Laureatefor Physics. (c) TheAbdusSalam International Centrefor Theoretical Physics(ICTP).
Table 1| Research expenditures

\begin{tabular}{lcc}
\hline & $\begin{array}{c}\text { GERD } \\
\text { (\% world) }\end{array}$ & $\begin{array}{c}\text { GERD/GDP } \\
\text { (\%) }\end{array}$ \\
\hline Western Europe & 27.8 & 1.8 \\
\hline Former Soviet Union & 1.2 & 0.6 \\
\hline North America & 36.7 & 2.4 \\
\hline Latin America & 3.6 & 0.6 \\
\hline $\begin{array}{l}\text { Southern M editerranean } \\
\text { countries }\end{array}$ & 1.5 & 0.6 \\
\hline Sub-Saharan Africa & 0.5 & 0.3 \\
\hline Industrial Asia & 20.2 & 1.9 \\
\hline China & 4.3 & 0.5 \\
\hline India & 2.1 & 0.8 \\
\hline Rest of Asia & 0.9 & 0.4 \\
\hline Oceania & 1.2 & 1.3 \\
\hline GDP
\end{tabular}

GDP, gross domestic product; GERD, gross expenditure on research and development. Source: Indicateurs 2000 , O bservatoire des Sciences et Techniques (OST), Paris.

of the imported equipment. The need to import spare parts from developed countries sometimes created further unexpected operating costs, while the dependence on foreign expertise caused political tensions. In addition, developing countries only assembled technical products imported from other countries. Although these activities created some jobs, they did not help to upgrade the skills and knowledge of local manpower.

$\mathrm{n}$ the meantime, the countries of the North realized that scientific knowledge contributes to economic development and to the creation of jobs. Research areas, such as computer technology and informatics, biotechnology and the space industry, have had a great impact on all sectors of society, and have ushered in the concept of a knowledgebased society in which technology is largely a by-product of research-albeit an important one from the economist's point of view. All this has helped to convince the public and the political authorities of the benefits of increasing resources 
for scientific research, especially if it is linked to industry. As a consequence, the gap in scientific expertise between developed and developing countries has increased, and the technological gap has widened even further.

Meanwhile, a few leaders in science and politics realized that simple technology transfer is not the solution to enable developing countries to tackle their problems and that they should be helped through the transfer of knowledge. A small number of international research and training institutions were founded to train scientists or to study problems that are of crucial interest to developing countries. One such example is the International Centre for Theoretical Physics in Trieste, Italy (www.ictp.trieste.it), founded by the late Nobel Laureate Abdus Salam (Fig 1), which organizes many graduate and postgraduate training courses for students from developing countries. Another example is the Consultative Group on International Agricultural Research in Washington, DC, USA (www.cgiar.org), an organization that funds scientific research and researchrelated activities in the fields of agriculture, forestry, fisheries, policy and environment, in research institutes located in developing countries.

$\mathrm{B}$ ut such training and funding activities, although clearly a huge help, are not sufficient. To reach a critical mass of scientists, developing countries that plan to engage in a specific field of research need to invest more funds and efforts in human potential as well as in research infrastructure. In fact, scientific infrastructures have become much more important than they were in the past, because of the increasing complexity of research projects, be they in physics, biology or chemistry. It is therefore important that developing countries create their own research infrastructure to give their scientists access to urgently needed facilities. As the cost of such facilities is relatively high, several interested nations can cooperate to build and maintain shared research resources. A recent example of such an international cooperation is the Synchrotron-light for Experimental Science and Applications in the Middle East (www.sesame.org.jo). This facility is located in Jordan, owing to the personal interest of $\mathrm{H}$ is Majesty King Abdullah II, and will be administered and supervised by the
United Nations Educational, Scientific and Cultural Organization (UNESCO). The founding member countries are Bahrain, Egypt, Iran, Israel, Jordan, Palestine, Pakistan and Turkey. Kuwait and Libya are, for the moment, listed as observers and other countries have expressed interest. The centre will be used as a research facility by almost 300 research groups that have already been identified in the region, but it will also devote much of its time to the training of scientists.

\section{Even if developing countries decided to increasetheir spending on $R \& D$, without adequate planning it would still be difficult for them to conduct and support research in an efficient way}

The creation of such centres was triggered by the idea that the disparities in research between countries of the North and South should be addressed through better scientific education. In this regard, the promotion of scientific excellence is important and a few outstanding scientists and/or research groups in a country can set an example that others will follow. However, examples of success are few and far between, and capacity building in science is much more complex than simply giving more resources to specific research groups. It also requires a legal, institutional and financial framework, scientific education at all levels and research infrastructures. The sad reality is that most scientists in the developing world work under difficult conditions and without any recognition of their importance (Harris, 2004). Consequently, the best and brightest-those who could act as shining examples for others- often decide to emigrate, mainly to the USA and Europe, where they find plentiful funding, good research environments and, probably most importantly, appreciation of their work. This 'brain drain' problem is the cause of deep frustration in developing countries and it is hotly debated in intergovernmental circles.

In effect, these countries need to do even more to create a sound research base, and the process has to start with changes at the political and social level.
To increase this awareness, particularly in developing countries, the member states of UNESCO and the International Council for Science (ICSU) organized a World Conference on Science (U N ESCO, 1999a), which took place in 1999 in Budapest, Hungary. The participants of the conference eventually came to the conclusion that scientific knowledge, and not just technology, is important for developing countries, and that these countries should create and improve their own educational systems and scientific expertise rather than relying on the import of knowledge from more advanced countries. Equally important, the conference attendees reached a consensus that improving science and technology is a task for all sectors of society, and not just scientists and engineers (laccarino, 2000).

By the same token, society should have an understanding of the role of science and technology, and its importance for social and economic development. Technological progress drives economic growth and development, creates jobs, contributes to higher agricultural yields, improves human health, and makes possible the production of higher quality consumer goods and services at lower prices (Altwaijri, 2000). Judicious investments in science and technology therefore have a substantial pay-off in increased productivity, wages and living standards. Furthermore, developing countries need to improve their research capacity to deal with inherent problems in their countries that are of no immediate concern to more advanced countries. Once developed for specific purposes, this knowledge and experience will then be useful for the whole socio-economic progress of the country.

\section{... a few leaders in science and politics realized that simple technology transfer is not the solution to enable developing countries to tackletheir problems...}

The agreement reached at the World Conference on Science (UNESCO, 1999b) helped to raise awareness of the importance of science and technology for development, and eventually brought the topic to the attention of many politicians. Only 


\section{MALARIA CAUSESPOVERTY}

M alaria affects between 300 and 500 million people globally, and morethan 2 billion areat risk - the vast majority in developing countries. In addition to an enormous amount of human suffering, malaria al so causes poverty: infected people are debilitated and unable to work; business does not invest in affected countries because workers are often unable to work; and the tourism industry is affected because of the fear of contagion. M alaria kills 1.5 million people every year, but many more die as a consequence of poverty (seefigure below; Sachs \& M alaney, 2002)
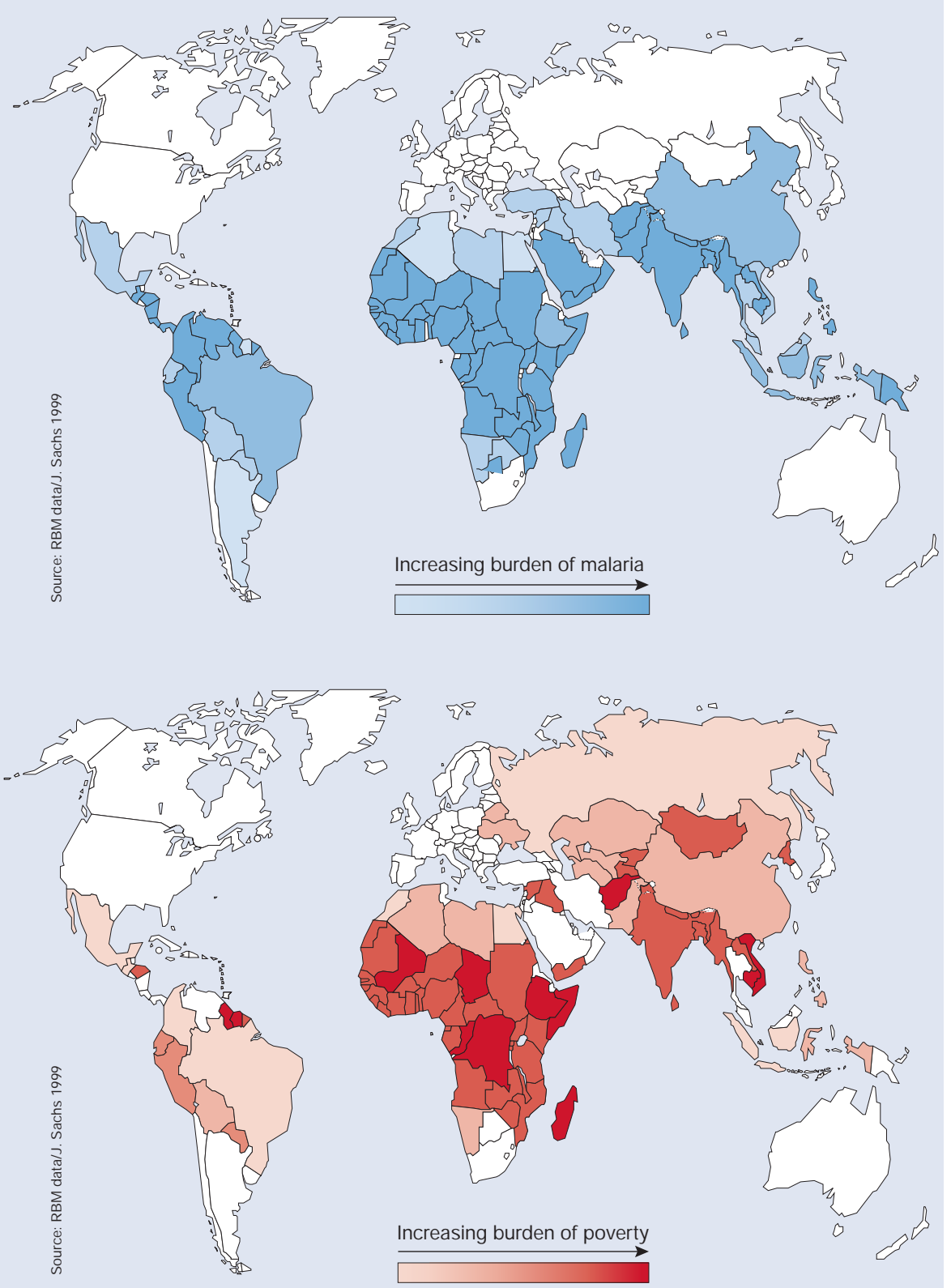

Malaria is caused by the protozoan Plasmodium falciparum, which is transmitted by mosquitoes belonging to the genus Anopheles. The disease can beeradicated either by destroying the protozoan in theinsect or in humans, or by killing theinsect vector. Any attempts to find an efficient vaccine against Plasmodium have, so far, failed and anti-malarial drugs have become increasingly ineffective owing to the appearance of resistant plasmodia. However, it is possible, in principle, to fight the vector Anopheles; for example, through the production and spread of genetically manipulated (Alphey et al, 2002) or sterileinsects. Scarce resources are devoted to this type of research, although similar wellfinanced projects to control fruit-damaging flies in Europe and North America are proving successful. a year later (September 2000), the Millennium Summit-although not specifically devoted to science and technology-decided to set up a task force on Science, Technology and Innovation, which recently produced a report on the role of science and technology in development (Millennium Project, 2000). Also, the InterAcademy Council recently issued a document that gives detailed instructions on ways and means to develop research capacity (InterA cademy Council, 2004). I think, however, that developing countries should not be given instructions: they should decide their priorities in an autonomous way, after consideration of the specificity of their needs.

$t$ is not easy for developing countries to build scientific capacity. Most of them, especially the least developed, suffer from an acute shortage of skilled professionals. For these countries, building an integrated system of scientific education and research is a long-term goal, whereas they have many pressing short-term priorities that need urgent attention. In addition, every country has its own peculiar set of impediments to development, ranging from desertification to local diseases to malnutrition, which require specialized knowledge and understanding to resolve (see sidebar). However, this is just one more argument in favour of investing in education and research, because only these activities can create the necessary knowledge and technology to find local solutions to problems in areas as diverse as sanitation, nutrition, food, water supply and purification, energy and communication. M oreover, developing countries cannot forever base their economies on the production of primary or low-quality manufactured goods, which are characterized by low productivity and low wages (Iaccarino, 2001).

Each country has its own physical and human resource endow ments that need to be defined and strengthened so that they can be used efficiently. Furthermore, stages of development cannot be sequential, starting with basic education and later concentrating on higher education, but must take place concurrently. This requires that parliaments and governments provide a legal, institutional and financial basis for research capacity, including incentives for further investment and transfer of research results into applications, products 


\section{... the promotion of scientific excellence is important and a few outstanding scientists and/or research groups in a country can set an examplethat others will follow}

and services. In this way, science can also help traditional sectors in manufacturing and agriculture by providing improved tools to increase productivity. Education and research together could therefore help poor countries to come out of isolation and exclusion, and empower them with knowledge and tools to actively participate in, and benefit from, the technologically sophisticated global economy.

In addition, it is also becoming more evident that all countries are responsible for tackling the growing environmental problems that have an impact on the future of our planet. Increased urbanization and certain industrial and agricultural activities are causing unforeseen changes in the biological, chemical and geophysical realms of the Earth. We face hitherto unprecedented challenges in the form of air and water pollution, new disease epidemics, ozone depletion, drought and ecological disasters. The global need for sustainable and integrated science policies and preventive measures is therefore imperative for the survival of our increasingly interdependent and fragile world and its life-support systems.

$\mathrm{H}$ ow ever, developing countries have many other problems and priorities, and it is often hard to find an appropriate place for science and technology among these. This is clearly a societal problem and not just one of economic development. The participants at the World Conference on Science therefore agreed on, and proposed, national and institutional strategies to strengthen scientific research in developing countries.

The first step would be to build a national consensus on the crucial role of science and technology in improving the human condition, as well as a wide awareness of the need to raise research budgets (H addad \& W olff, 2001). It is important to realize that science will have to compete with other equally legitimate sectors for limited resources. Moreover, the bargaining for funds must involve not only the interests of organized groups but also the public. It is therefore essential to develop a constituency for science and technology within the country, and to formulate an advocacy strategy that describes how science can contribute to economic growth and poverty reduction.

Scientists, researchers and intellectuals in developing countries need to take the lead in these discussions and bring research to the mindset of political, financial, business and community leaders. They should emphasize the centrality of science for development, as well as the crucial importance of public policy and investments to its success. But the scientists will need to understand and overcome the suspicion among local and international communities that they could be lobbyists for elite groups with little understanding of other essential needs. It is important to accept the fundamental importance of better financing of basic education and recognize that higher education should not be a privileged sector, but, at the same time, should become more efficient. Only by accepting these premises can the research constituency argue for the fundamental importance of knowledge generation and the crucial role of public support.

$T$ here are several strategies for achieving success (Haddad \& W olff, 2001), although they might vary among countries. A first step would be an in-depth analysis of the national situation of science and technology in the country. This should cover not only the training of qualified scientists and engineers, but also strengthening the environment for innovation, and creating and sustaining a small number of crucial institutions while ensuring transparency, accountability and adequate financing.

\section{... it is also becoming more evident that all countries are responsible for tackling the growing environmental problems that have an impact on the future of our planet}

Building on the results of such an analysis, a national team of business people, scientists, engineers, educators, politicians and other stakeholders should start discussions with officials from the ministries of finance and economics. The task of this team would be to identify problems and priorities in the national innovation system and, eventually, to define a strategy that includes regional and international alliances.

\section{It isfundamental to decide on a limited number of areas essential to economic and social development that must be developed, so as not to overstretch limited resources}

This group would then decide on the crucial objectives on which science and technology should focus to help the development of the country. These objectives should be simple and clear, and translate into a few key areas and actions. It is fundamental to decide on a limited number of areas essential to economic and social development that must be developed, so as not to overstretch limited resources. A small number of topics will also make it easier to promote their support. Because of these restrictions, the importance of outside assessments of research productivity of individual researchers and institutions should be stressed. These reviews should identify individual key institutions that need to be created or expanded.

As stated in one of the documents approved at the World Conference on Science: "All countries should systematically undertake analyses and studies on science and technology policy, taking into account the opinions of all relevant sectors of society, including those of young people, to define short-term and long-term strategies leading to sound and equitable socio-economic development" (U NESCO, 1999c). Those who take the lead in developing a national agenda for science and technology should therefore hold a nationwide seminar to discuss these issues, the results of which would form the basis for further discussions with political decision makers. If this process is successful, science will become a more pressing priority in the country so that more resources can be allocated to research.

The argument that science is not part of the culture of developing countries must be strongly rejected. In fact, the birth of 
modern science at the time of the Renaissance built on great civilizations of the past and owes much to the medieval Islamic world, which elaborated on Hellenistic science and transmitted it to Europe (laccarino, 2003). By contrast, developing countries urgently need scientific knowledge on which to build applied research to develop solutions for their local problems. All participating countries, most of them developing nations, endorsed the conclusions of the World Conference on Science. But, after 1999, there was only limited improvement of science and technology in developing countries, and the pressures of globalization often resulted in a more marked specialization of tasks, which actually decreased the need for skilled manpower in the South. To reverse this trend, all sectors of society should be involved in science and technology through the generation of a cultural and social environment that is suitable for scientific progress while realizing the role of science and technology in the development of a country. Science cannot be imported from richer countries, but must be developed locally. Science cannot be given: it should be taken.
REFERENCES

Alphey L et al (2002) Malaria control with genetically manipulated insect vectors. Science 298: 119-121

Altwaijri AO (2000) in World Conference on Science: Proceedings. www.unesco.org/ science/wcs

Haddad W, W olff L (2001) D ebt relief for S\&T. U nited N ations Educational, Scientific and Cultural O rganization. www.unesco.org/ pao/debt1.pdf

Harris E (2004) Building scientific capacity in developing countries. EMBO Rep 5: 7-11

laccarino M (2000) in World Conference on Science: Proceedings. www.unesco.org/ science/wcs

laccarino M (2001)A vision for European science: more integration and a long-term policy is needed. EMBO Rep 2: 259-262

laccarino M (2003) Science and culture. EM BO Rep 4:220-223

InterAcademy Council (2004) Inventing a Better Future: A Strategy for Building Worldwide Capacities in Science and Technology. www.interacademycouncil.net/report.asp?id $=6258$ Millennium Project (2004) Interim Report of Task Force 10 on Science, Technology and Innovation. www.unmillenniumproject.org/documents/ tf10interim.pdf

Sachs), M alaney P (2002)The economic and social burden of malaria. N ature 415: 680-685

UNCSTD (1979) UN Conference on Science and Technology for D evelopment. U nited N ations, N ew York, USA

UNESCO (1999a) World Conference on Science: Proceedings. www.unesco.org/science/wcs
UNESCO (1999b) World Conference on Science: Declaration on Science and the U se of Scientific Knowledge. www.unesco.org/science/wcs/eng/ declaration e.htm

UNESCO (1999c) World Conference on Science: Science Agenda-Framew ork for Action. www.unesco.org/science/wcs/eng/framework.htm

This text is an elaboration of a speech given at the Euro-Mediterranean Forum on S\&T Cooperation in the Mediterranean Region, which was held in Capri, Italy, on 4-60 ctober 2003.

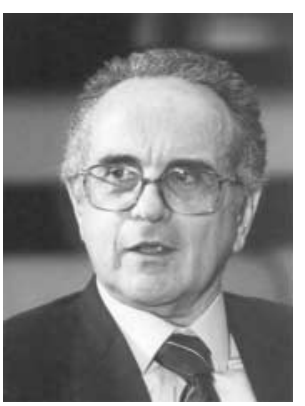

Maurizio laccarino, Secretary General of the UNESCO/ICSU World Conference on Science, is at the Institute of Genetics and Biophysics at the Consiglio Nazionale delle Ricerche in Naples, Italy.

E-mail: iaccarin@iigb.na.cnr.it

doi:10.1038/sj.embor.7400159 